incertidumbre de que quizá "había sido ella una Trifona" (p. 264) ${ }^{8}$ le hace aceptar como suyo "el espíritu falso, torcido, de la poetisa que por algo el buen sentido vulgar desprecia" (p. 264). Ana Ozores llega a ser espectáculo de su burla. Se objetiviza en algo distinto de lo que es y se desintegra en la ironía 9 .

Al reducirse a la poetisa vulgar, a "aquel ente híbrido y abominante de que se hablaba en Vetusta como de los monstruos asquerosos y horribles" (p. 79), Ana-Regenta se olvida de su complejidad individual. La Ozores cambia su identidad por una imagen, réplica de Trifón Cármenes a la vez que expresión de sus recuerdos. Los sentimientos de vulgaridad, desprecio y falsedad se suman a la visión de su yo. El ridículo nace del contraste entre "el mundo de las cosas grandes, las ideas puras y bellas, confundidas con la prosa y la falsedad y la maldad" (p. 264).

Estos cambios de identidad que ridiculizan a la Ana auténtica nos demuestran las fluctuaciones degradantes que proyecta su personalidad, en circunstancias especiales, a la mirada de quienes se niegan a atender la complejidad de la estructura unitiva de la Regenta. Estas metamorfosis no son más que el resultado de un proceso inverso a los que producen los cambios de identidad espiritualizadores e idealizantes. Sólo la mirada objetiva de quien ausculta sin pasión el interior y el exterior del yo de Ana nos conduce a la auténtica individualidad y personalidad de Ana Ozores, la mismísima Regenta de Vetusta.

Franklin Proaño

Denison University.

\title{
ALGO SOBRE LAS CRIATURAS DE JUAN BENET
}

En varios relatos y novelas Juan Benet presenta un mundo cuya característica fundamental está bien definida por Gonzalo Sobejano al atribuirle una "realidad enrarecida"'. Enrarecida en dos sentidos: insólita, por una parte, y por otra, como desplazada y menguada en su cohesión y densidad por la invasión de un elemento de fantasía que coexiste con ella y la penetra.

Seis son, hasta hoy, las obras narrativas - no a todas ellas se las puede llamar novelas- en las que Benet presenta ese mundo², pero dos ofrecen

8 Trifón Cármenes era "el articulista de necedades ensartadas en lugares comu* nes; de retórica fiambre, sin pizca de sinceridad" (p. 264).

9 P. ILIE (op. cit., p. 45) advierte este proceso: "The structure of the ego disintegrates by means of a conscious act of self-objectification. Within this posture it is possible to assume, at the same time, an actitude of irony. Self-mockery thus becomes another form of self-corrosion. But, since only one part of the individual eats away at the other, the individual himself remains sufficiently intact to watch the drama of his own self-destruction".

1 Gonzalo Sobejano, Novela española de nuestro tiempo. En busca del pueblo perdido, Madrid, 1970, p. 403.

2 Nunca llegarás a nada, Volverás a Región, Una meditación, Un viaje de invierno, La tumba y La otra casa de Mazón. Estando en prensa estas líneas apareció Sub rosa, libro de relatos. 
su imagen de manera más completa y homogénea. Son las extensas novelas Volverás a Región y Una meditación. En ellas he de basar estas anotaciones ${ }^{3}$.

Inútil sería la presentación de su anécdota, casi accesoria. Benet es deliberada e intensamente polisémico y, así, resulta que dos autores como Sobejano y Gimferrer ${ }^{4}$ dan interpretaciones diferentes a ciertos acontecimientos narrados en Volverás a Región. También es verdad que cualquier lector puede encontrar variantes en cada relectura.

Lo que más interesa -además de algunos de los largos pasajes ensayísticos- es el mundo que palpita en ese sitio mítico y real, regional y universal a la vez, que es precisamente Región, la comarca que, supuestamente aislada entre las montañas de León y Asturias, puede representar a la España de posguerra o a cualquier otro país en circunstancias semejantes.

La geología y la topografía nutren extensos pasajes benetianos, y en ellos se aúnan la ciencia y la poesía. Varios autores han escrito ya sobre esto; sólo diré que a este tipo de presentación del paisaje podría aplicarse, en diversa medida y con diverso matiz (el de lo fantástico) la misma expresión con que Antonio Machado califica su propia obra: la de "geografía emotiva". Esta geografía -indefectiblemente real e irreal al mismo tiempo- y una toponimia también ambivalente, contribuyen a crear el ámbito propicio para albergar a las extrañas criaturas de Benet. Se mencionan, en relación con la guerra, "los campos del Jarama y el Tajo... Brunete y... Teruel" (Var, 75), pero también están presentes los imaginarios Puente de doña Cautiva, Macerta, Nueva Elvira, San Salvador, Retuerta, el río Formigoso, los collados de Socéanos y La Requerida, la cumbre de El Monje... y la misma Región.

En este ambiente resuena y se prolonga el leitmotiv de la ruina notado por todos los críticos, la destrucción de un grupo humano, de aproximadamente tres generaciones. Pero lo más importante, a mi modo de ver, es la causa profunda de esa destrucción, que, en las novelas de Benet, no es precisamente la guerra civil, sino el miedo. Dice uno de los personajes clave: "Yo creo que por aquel tiempo [tiempo que, en Benet, es siempre impreciso] surgió el miedo a sí mismo y sobre todo a sus semejantes" (Var, 216 y 218). Pero el miedo que mueve o paraliza a todos los personajes benetianos es, principalmente, el miedo al amor. Esto está muy explícito en Una meditación, donde repetidamente el autor declara la preeminencia del "ordo tremoris" sobre el "ordo amoris"5 y afirma que la humanidad es "la especie que se reproduce con temor" (Um, 314).

Me parece importante destacar este aspecto que, por lo demás, no se circunscribe a las dos novelas que examino, sino se extiende a toda la obra benetiana. El temor empieza por revelarse en el paisaje mismo: “... un monte áspero, cubierto de jara y espliego y algún enhebro muy

3 Citaré por siglas las ediciones siguientes: Volverás a Región, Destino, Barcelona, 1967 (Var); y Una meditación, Seix Barral, Barcelona, 1970 (Um).

4 G. Sobejano, op. cit., y Pere Gimferrer, "Sobre Juan Benet", Plural, México, 1973, núm. 17.

5 Véase pp. $140,246,247,248,282$, entre otras. 
anciano y enano..., el cañón de color de piel de elefante..., las pocas piedras en pie de una cerca abatida. Pero cabe decir que si en nuestro tiempo tal lugar ya no sirve para levantar el vuelo de la imaginación de nadie, al menos mantiene el estado de temor" (Um, 273-274; las cursivas son mías). Al referirse ya a la identificación "amor-temor" ( $U m$, 297), Benet es tan explícito que debo limitar al extremo la cita de pasajes": El hombre es "una especie medrosa..., que... en el amor... empieza a entrever la imagen de su verdugo..." (Um, 140); "el miedo es siempre real y el amor... una invención especulativa para superar aquél sin querer combatirlo" (Var, 299); "no se puede amar sin tener miedo... porque el amor no es más que una forma del horror..." ( $U m$, $27 i$; “. . . en toda grave historia de pasión... alienta, como no puede ser de otra manera, el horror, el miedo y la repugnancia por la especie humana..." (Um, 241).

Con su habitual oscura morosidad, en varias partes se refiere a la expectación o consumación del acto sexual, y siempre menudean las alusiones al miedo y al dolor. Así en las páginas 139 a 141 de Una meditación: "... es un medio dominado por el temor..."; “...la razón vino luego... para superar el estado de temor..."; "... para superar el estado de temor con el dominio de la circunstancia..."; ". . . teme, teme, teme, sólo el temor te será de ayuda..."; “...teme, teme, no te sustraigas al miedo..."; “...el temor se hizo patente..."; "El miedo antıcipa más que cualquier otro sentimiento..."; “... una incurable desazón que busca en el ordo tremoris... el orden austero de un rencor mantenido... '; ". . si bien un temor cualquiera puede desvanecerse, el ordo tremoris, en contraste, no prescribe jamás..."; "...lo que verdaderamente importa es vivir temiendo..."; "...permitir al hado que cumpliera sobre su cuerpo los sacrificios que el miedo había anticipa. to...", etc. Y en otro lugar: “... el hombre falo, al abandonar la gruta del sexo, se encontrará envuelto en lágrimas y amedrentado..." ( $U m$, 194).

Dentro de este ordo tremoris actúan las criaturas de Juan Benet, todas singulares, merced a esos "procedimientos extrañantes" de que habla Sobejano (op. cit., p. 403). Sm embargo, se puede establecer entre ellas una distinción fundamental: las meramente raras, cuyas vidas transcurren, a pesar de insólitos acontecimientos -uno de ellos, la guerra civil- dentro del margen de lo posible, y aquellas otras que, en cualquier forma, rebasan esos límites para entrar en el terreno de lo maravilloso. Tal vez pueda llamárselas fantásticas conforme a la teoría de Todorov ${ }^{7}$, ya que la deliberada calidad proteica de los seres y de los aconteceres benetianos permite siempre vacilar entre la certidumbre y la incertidumbre de su "realidad".

Muchos personajes de Benet -quizá formen mayoría- son simple-

6 El fragmentarismo de la mayoría de las citas se debe a la complejidad de la sintaxis benetiana, ya también señalada por todos sus críticos.

7 Cf. Tzuetan Toborov, Introducción a la literatura fantástica, Buenos Aires, 1972. caps. I y II. 
mente extravagantes: Sebastián, Marré ${ }^{8}$, el muchacho idiota, Gamallo, Ia prima Mary, la pareja formada por Leo y Bonaval, el matrimonio Rumbal, la familia del narrador de Una meditación, Rosa de Llanes, la familia Ruan, el patrón y el capataz de la mina, Antonio y Camila Abrantes... y otros muchos. Sin embargo, las líneas de acción de todos y cada uno de estos personajes se empalman y cruzan tan inextricablemente con las de los obviamente fantásticos, que acaban por participar, al menos en algún punto, de su calidad fabulosa.

En una entrevista Benet afirma de Una meditación algo que, con variantes, es aplicable a Volverás a Región: “... aparece como... un largo discurso. Este discurso es la memoria de un señor, que es un joven antes de la guerra, y vive en un país imaginario... Este señor se equivoca, confunde y, sobre todo, como todo narrador de muchas cosas, no dice la verdad y produce en su propio discurso sus insidias y, por lo tanto, se contradice... El discurso está basado en una serie bastante cíclica, porque se va repitiendo en unas anécdotas que este personaje narra, y tras cada narración divaga y se mete en consideraciones sobre cada caso, sobre cada sentimiento, sobre cada motivación, muchas de ellas prolijas, pesadas, con grandes pretensiones analíticas..."'. Efectivamente, todo eso es Ia obra narrativa de Benet, y hay que mencionar también la extraña belleza de algunos de los largos ensayos interpolados, cuyo tema puede ser la ciencia, la filosofía y el psicoanálisis, entre otros. También hay que hacer resaltar lo que es el objeto principal de estas notas: la prosipoética, extravagante y, a veces, grotesca condición de los personajes.

Un sujeto presente en las dos novelas estudiadas ( $y$ en casi todas las demás obras narrativas de Benet) es el doctor Daniel Sebastián, casi protagonista, junto con su interlocutora, de Una meditación. En sí mismo, no pasa de ser un médico misántropo, con un desdichado pasado amoroso y un matrimonio sin amor, pero su liga con otros personajes lo contamina de irrealidad. En primer lugar, están su padre y su madre: el primero, telegrafista prodigioso, que logra obtener mediante el telégrafo --Ilamado siempre "la rueda"- comunicaciones proféticas y ultraterrenas. Sebastián habla de su padre: "Su única pasión era la rueda" (Um, 123) "...bajaba al cuartucho a estar con ella a solas hasta las primeras luces del día" ( $U m, 124)$ y refiriéndose al aparato milagroso, después de la muerte del padre: “...la rueda maldita que giraba a una velocidad endemoniada y que perforaba en el papel lo que a cualquier insensato se le podía ocurrir en el otro extremo de la península o en el más allá" $(U m, 217)$. Y también: "...entraba yo en aquella desierta oficina y veía la rueda inmóvil y las interminables espirales de papel perforado que habían invadido el suelo y la mesa (una especie de solitaria segregación postmortuoria del espíritu de mi padre)" (Um, 130).

En cuanto a su madre, era una mujer que, aparte de alimentarse de berzas, podía hacer lo que Benet refiere en una nota al pie: "Su madre,

8 La interlocutora de Sebastián en Una meditación. Una sola rez aparece su nombre en la novela y está mencionado por ella misma (p. 115).

9 ANTonio Núñez, "Encuentro con Juan Benet", Jins., 1969, núm. 269. 
sentada como una reina, boquiabierta por el espanto, inspiró tanto aire que se levantó de la silla como un globo y, sueltas las amarras, se deslizó majestuosa y sin decir una palabra a la habitación del piso alto de donde ya no salió sino para abandonar la casa" (Um, 109). El contexto total del pasaje no sugiere una interpretación metafórica.

Pero la máxima contaminación de irrealidad de Daniel Sebastián se da a causa de su relación - únicamente de su parte, amorosa-con su paciente María Timoner. Caminando una noche "alguien le silbó... "Acércate», dijo una voz apagada... No acertó a vislumbrar sino una cabeza envuelta en sombras... acaso no tenía pelo y protegía su calvicie con un pálido y gaseoso velo que se cerraba por debajo de la barbilla, a la altura de la boca..., de su boca manaba un aliento que no era cálido ni fétido pero tan seco que sus palabras parecían salir de un instrumento de barro". (Um, 237-238). Esta llamada "visita" es la muerte, cuyo diálogo con Sebastián sirve para evitar que se adueñe de María. En cuanto a ésta, no puede considerarse más que como un personaje envuelto en sucesos muy extraños pero que, aun incluyendo su truculento final, no rebasan el marco de lo posible. Si acaso la roza la irrealidad, es en la persona del misterioso tahúr que la gana en el juego entablado entre él y el novio o amante de la mujer, el militar Gamallo. Pero sobre esto he de volver más adelante.

Por lo que hace a Marré, la interlocutora de Sebastián e hija de Gamallo, no es más que una mujer conservada como rehén por los republicanos, seducida y prostituida durante la guerra y que, ya en la madurez, vuelve a Región para buscar un paliativo a las secuelas morales de sus experiencias pasadas. Sin embargo, el personaje está rodeado de misterio en su antigua relación amorosa con ese inasible y ambiguo ahijado del doctor Sebastián -que, además, puede ser el hijo de María Timoner-, en su contacto con el personaje llamado "Muerte", y en el fin de su propia vida que, según la interpretación de Gimferrer (loc. cit.), se debe a un disparo de ese Numa casi sobrenatural, que jamás aparece directamente en las novelas.

El ahijado es uno de los más diluidos personajes de Benet, a pesar de estar tan presente en el relato de Marré; "Muerte", tiene el don de las transformaciones: "Un mismo nombre sirve para dos Adelas, y una de ellas puede metamorfosearse de vigilante del precioso rehén -la Mujer, hija de Gamallo- en alcahueta de un burdel y llamarse entonces Muerte. Y algo después reaparecerá como suegra de la mujer que Adela vigiló y Muerte cuidó, desempeñando siempre la misma abominable función carcelera"10. En cuanto a Numa, no aparece jamás, sino por referencias, pero preside ambas novelas. "Su historia -o su leyendaes múltiple y contradictoria; se asegura por un lado que se trata de un superviviente carlista...; también cunde la creencia de que su existencia se remonta a muchos años y decenios atrás: un monje... Se afirma

\footnotetext{
10 Este pasaje procede del artículo titulado "Una región laberíntica que bien pudiera llamarse España", que está dividida en cuatro partes: "Labcrintos del espa. cio", "Laberintos del ticmpo", "Laberintos del personaje" y "Laberintos del discurso": Ricardo Gullón, fins., 1973, núm. 319.
} 
también que no se trata sino de un militar que todos hemos conocido y que, habiendo amado a una mujer hasta la locura, se fugó despechado y se retiró allá para ocultar sus voluntarias mutilaciones y cobrar venganza en el cuerbo de sus seguidores" (Var, 251). Hago notar que esta tercera posibilidad parece aludir a Gamallo, para desconcierto del lector, que sabe que éste murió repentinamente hacia el final de la guerra (Var, 286). Sin embargo, lo más ordinario es que se hable de Numa como del viejo pastor y guardián de la solitaria y remontada finca de Mantua, que da muerte a cuantos se atreven a llegar hasta allá. Numa está omnipresente en Volverás a Región y también, aunque en alusiones menos explícitas - ya no son necesarias-, en las siguientes obras de Benet. Numa "es torpe, viejo y tuerto y -al decir del vulgo- de su bandolera cuelga todo un rosario formado con las muelas de oro que ha arrancado a sus víctimas; a la llegada del otoño, cuando da por terminada su temporada de caza, acostumbra a cantar una canción muy larga y muy triste, que viene a durar diez o veinte días... En invierno se viste como un pastor de la taiga, una pirámide de lanas vírgenes coronada por un morrión de pieles de zorro y conejo... (Var, 250) : “... se llega a pensar hasta oué punto es verosímil esa maldición, hasta qué punto el futuro... ha de seguir determinado por la cerrazón. y la puntería y el insomnio de ese viejo guarda. Quizá ya no existe sino como cristalización del temor .. "(Var, 221; yo subrayo).

Otros personajes que parecen no tener nada de irreal o fantástico son los cuatro que Benet presenta, en grupo, de la siguiente manera: "Jorge [frecuentabal las reuniones de aquellos amigos suyos de Región y la ribera, Rosa de Llanes, los hermanos Abrantes [Antonio y Camila], etc., que por tener todos en común aquella especial orfandad... habían optado por un tipo de conducta considerado como el más licencioso" ( $U m$, 110). Y en otro sitio: Jorge Ruan "buscó refugio en Rosa de Llanes, una mujer mayor que él y tan avezada a toda clase de lances amorosos que siempre estaba dispuesta a iniciar uno nuevo... Con toda seguridad fue ella la que le introdujo en casa de los hermanos Abrantes, que ya por entonces daban bastante que hablar..." (Um, 247-248). Estos personajes van a entrar al terreno fantástico, por sus relaciones con otros, o por las que hay entre ellos mismos.

En primer lugar, Rosa se liga a un recién llegado, cuyo nombre da Benet en dos versiones diferentes. Dice el narrador: "... aquel menudo Andarax, tan delicado de salud y tan dado a la farmacopea que ya no nodía dar cuatro pasos sin llevarse una pastilla a la boca, que vivía envuelto en lágrimas y paños higiénicos en la casa de Rosa de ILlanes..." (Um, 62). "... Como dije, se llamaba Andorax, o algo así...; no llevaba todavía un año merodeando por Región cuando Rosa de Llanes -que era bastante más alta que él- se lo llevó a su casa con el pretexto de administrarle la medicación adecuada... Con el rapto su condición fue cambiando...; sobre todo dejó de ser un hombre agresivo o impulsivo, sentado siempre en una silla de anea a la que se había acondicionado y encajado un orinal... cubiertas las piernas con una manta escocesa, los ojos llorosos y emocionados... y un dedo índice entre las páginas de un grueso volumen de Leopardi, elegantemente caído 
en su regazo..." (Um, 253-255) . "No se volvió a hablar de aquella perla que, se decía, Andarax se había tragado un día que se abalanzó sobre ella...; hubo quien afirmara que no sólo el secuestro sino el largo y amagado cautiverio y la consiguiente metamorfosis de Andorax se debía a la permanencia de la jova en su aparato digestivo, que había engendrado sub specie simili la glándula defensiva...”; “...el régimen de continuas purgas a que Rosa tenía sometida a la persona mencionada ut supra había terminado por hacer enfermar a la propia glándula que de aparato defensivo se había convertido en reproductor de perlas..., que, al parecer, Ut Supra depositaba todos los meses... sobre un orinal de China... ambos habían acordado el voluntario cautiverio que debía prolongarse hasta que Rosa pudiese lucir un collar de cien cuentas..." (Um, 255) .

En cuanto a los hermanos Abrantes, el hecho de que mantuvieran o no relaciones incestuosas no toca propiamente a lo fantástico; pero sí lo toca el hecho de que un ambiguo misionero, invitado ocasionalmente a su casa, haya tenido motivo para maldecir a Camila y Antonio, de tal manera que sus maldiciones se cumplan en la cabeza de éste: "No parece atrevido asegurar que [aquel incidente] fuera el responsable de que las profundas entradas que amenazaban la cabellera de Antonio Abrantes... se hubieran transformado... en una calvicie casi completa, apenas simulada por unos pocos largos y rubicundos cabellos que... parecían resistir... el acoso del implacable misionero que todas las noches, en su cripta de Kumassa o de Brahmapuri, dedicaba unas horas al exorcismo arrancando pelos de un fetiche con cabellera de zanahoria, reproducción tosca pero indudable de la cabeza de Antonio Abrantes" ( $U m$, 249-250) .

Jorge Ruan es un personaje que pertenece a la realidad, aunque no puedo dejar de mencionar la extrañeza de su conducta erótica, de explicación mucho más psicoanalítica que sobrenatural: "Al parecer, siempre que Jorge poseía a una mujer la mordía en el cuello o en el lóbulo de la oreja y se acordaba de la rata" (se refiere a un incidente de su niñez). En sus relaciones sexuales con Camila, Jorge procuraba que hubiese en la habitación una rata enjaulada. Y dice el narrador: ". . la rata, por más presente, real y acongojante, debía hacerla también más atractiva... : no me parece aventurado suponer que cuando su cuerpo penetraba el de Camila... su pensamiento volaba, en el momento de sucumbir al orgasmo, hacia el anhelo imposible de hacer morir al animal con un mordisco en la yugular... Poco a poco... había de sustituir el cuerpo de Camila al de la rata". Además, había inducido a Camila al casi ritual "juego de las ratas": "Al bicho encerrado en la jaula lo azuzaban con un hierro caliente..., vaciaban sobre él, media botella de petróleo... Entonces - uno a cada lado de la jaula- abrían la compuerta y mientras uno, con el hierro, apremiaba a la rata a salir, el otro... bajaba una antorcha de cotones encendidos para formar una cortina de fuego que la rata atravesaba de un salto... para convertirse en un fulgurante haz de llamas que corría... despidiendo una columna de humo negro, denso y agrio, hasta que... carbonizada y retorcida. 
caía de espaldas crepitando y lanzando brasas, agitada por los últimos movimientos nerviosos..." (Um, 270).

Un personaje nunca descrito, nunca "visto" por el Iector, pero de tan fuerte presencia que - como Numa-contagia de irrealidad a todos los demás, es el Indio: "Todo el mundo sabía que había matado a su padre y que el humo que salía de su cocina era irrespirable; . . solía bajar en aquellas noches desde su caserío... a dialogar con su padre. Se ocultaba de todo el mundo, apenas le habia visto nadie" ( $U m, 152)$. "Nadie sabía por qué le llamaban el Indio; no había estado nunca en América, ni él ni ninguno de sus solitarios progenitores y antepasados... Había matado a su padre, como había hecho su padre con su abuelo, como hizo su abuelo con su bisabuelo; no se trataba de una tradición ni de una costumbre de familia, ni siquiera de una maldición, sino de un azar tres o cuatro veces repetido..., que tampoco debía, al parecer, ser por él mismo tomado tan en consideración como para evitar el engendramiento de un hijo. No lo tenía no porque lo temiera, sino porque -acaso-- lo buscaba con tal furor que atemorizaba a las pocas mujeres que debieron toparse con él. Temía mucho más a su padre, que todas las noches de riada se le aparecía en las aguas negras del embalse... Unos ojos amarillos muy tenaces y malignos lanzaban una luz vibrante...; se temía que debía ser algo más... que una aparición porque, al hablar, de su boca salían burbujas que sólo al romperse en la superficie de las aguas daban al sonido las palabras que llevaban dentro..." (Um, 153).

Algo semejante ocurre con la vieja barquera, especie de Caronte femenino que se encarga de transportar pasajeros de la mina de sílice al casino-balneario, ambos lugares igualmente fantasmagóricos. "Aquel que llegue al lugar - los pantalones arremangados por los tobillos-- sólo tiene que dar un breve silbido y al punto, encorvada y descalza, cubierta con una saya negra, saldrá de su guarida con un paso corto" (Var, 198). Después de atravesar el río "siempre se las arregla para embarrancar el esquife en la orilla de légamo negro, con un golpe tan brusco y violento que el viajero desprevenido por fuerza cae de espaldas, yendo a dar con el culo en el fondo encharcado de la embarcación. Es el momento en que -la muy bruja- echa a correr para ganar la orilla seca y tirarse por un prado para retorcerse de risa" (ibid.). Ia barquera tiene, como Muerte, el don de metamorfosearse: “. . .una pastora tocada a la usanza del país, apacienta el rebaño... Hay quien opina que no se trata sino de la vieja barquera, en uno de sus famosos travestis" (Var, 229).

Este personaje está estrechamente ligado a otro, que -igualmente ambiguo y misterioso- es el eje de uno de los episodios más notables de Volverás a Región: la partida de naipes que se prolonga durante un año y cuya apuesta es María Timoner. "Un día llegó [al barracón que albergaba a los mineros] un peón un tanto singular...; una vez por semana bajaba hasta el Torce para proporcionarse un baño completo del cuerpo, en una poza que escapaba a la vista de la barquera" (Var, 201). "Un día se llegó a saber -era sin duda una de las últimas tardes de un septiembre dulce y dorado- que, sentado sobre una piedra en el 
centro del río y completamente desnudo, durante un par de horas largas y placenteras en las que la vieja se aplicó a ello con el mayor mimo y esmero, había sido enjabonado y fregado por ella" (Var, 203). También recibe de la mujer un regalo singular: "Encorvada se dirigió a él, le agarró por los bordes de la camisa y le preguntó: - ¿Asi que eres tú? / ¿¿Qué es lo que soy yo? / -Eres tú, eres tú. ¿Cómo no me di cuenta antes?... Está bien, Io dicho, dicho está. Tómala, juégala como quieras; pierde cuidado y sobre todo, no seas prudente, no lo seas nunca, le dejó la moneda en sus manos y echó a correr; a bragas enjutas cruzó el río, en aquellos días en su mayor estiaje" (Var, 227-228). Era "una hermosa moneda de oro, del tamaño de un reloj de bolsillo... una moneda muy pesada, de oro de ley y cuño americano..." (Var, 207).

$\mathrm{Y}$ es aquí donde incide y participa de lo fantástico otro personaje al que antes he aludido sólo de paso. Gamallo pertenece de lleno a la realidad, una realidad casi histórica que se palpa en el relato de las acciones bélicas en que interviene. Es simplemente un militar mediocre que tiene una prometida o amante llamada María Timoner, que obtiene un ascenso de ocasión, que combate sin pena ni gloria como coronel franquista, que se olvida de su hija Marré, tomada como rehén por los republicanos y que muere al finalizar la guerra. Pero esta realidad sin relieve se transforma en la más desbordada fantasía cuando Gamallo entra en contacto con el jugador misterioso, protegido de la barquera; cuando, perdido ya todo lo demás, juega y pierde a su amante; y cuando el vencedor clava su mano, con una navaja, en el tablero de un juego que había durado "un tiempo vago, verano, otoño, invierno y primavera fundidos..." (Var, 232). Múltiples veces se aludirá a él en términos parecidos a éstos: “. . . un militar que ha perdido su guerrera, enfundado en una pelliza prestada entre cuyos pliegues, mientras lanza unas miradas oblicuas, esconde una mano vendada con unas hilas sucias y manchadas de sangre. Ya por aquel entonces acostumbra a morderse las uñas, incluso las de la mano herida que se lleva a la boca ayudándose con la otra" ( Var, 225).

Varios otros personajes presenta Benet, en sí mismos fantásticos y cuyas líneas de acción, al entrelazarse con las de los seres "normales", tienen el efecto de privarles de su normalidad: así las dos inaprehensibles hermanas, dueñas de la fonda de Retuerta, la mujer de Brabante, el penitente de la mina... Entre ellos tiene lugar preeminente Cayetano Corral: en un cobertizo que se había hecho fuera de la casa paterna "se pasaba las horas de luz estudiando..., y al caer el día se retiraba a descansar sobre su banco de trabajos manuales... o, mejor dicho, sobre aquel reloj paisano de caja negra y cuadrada, esfera circular y números romanos... que durante años se dedicó a renovar y perfeccionar hasta el punto de que del ejemplar original sólo habían de quedar los elementos estáticos" (Um, 77). Silenciosamente enamorado de Leo, una mujer que suele visitar su cobertizo, un día se entera de que ésta lo ha dejado por otro. "Que una pasión tan vehemente se convirtiera en pocos meses... en esa tranquila, solemne y escéptica aceptación de un acontecer sin sobresaltos era algo que ni siquiera el reloj podía comprender" ( $\mathrm{Cm}, 80)$. Pero Cayetano reacciona: "...se puso a tra- 
bajar sin descanso y con gran prisa... y alrededor de una medianoche... sin comunicárselo a nadie, puso el reloj en marcha" ( $U m, 287)$. "Un latido anormal fue tomando cuerpo y creciendo... se extendió a los alrededores, a toda Región y su sierra, y toda su comarca sacudida por aquel lejano y acompasado golpe que no cesaba ni de día ni de noche..., el poderoso latido que estaba minando todo el suelo patrio" ( $U m, 288)$. Finalmente, al incendiarse su cobertizo "no se le volvió a ver por allí; su padre -ignorante de la dirección que había tomado Cayetano al desaparecer- bajó al cabo de tres días para inspeccionar las cenizas en medio de las cuales - tan sólo con la caja un poco calcinada- milagrosamente había quedado en pie el reloj que - sin sonido ni tic tac- aún movía algo el péndulo..." (Var, 82).

Baste lo dicho para hacer ver, al nivel de los personajes, esa hábil imbricación de lo real y lo maravilloso que constituye uno de los principales recursos de Juan Benet. Quizá éste, junto con esa "incertidumbre como fundamento" de que alguien ha hablado"1, constituyan sus principales "procedimientos extrañantes". Tales procedimientos siguen produciendo su efecto en las novelas casi poemáticas Viaje de invierno y La tumba. En cambio resultan ya algo densos e ineficaces en La otra casa de Mazón, o quizá la forma híbrida (novela-teatro) adoptada por el autor no corresponda, en este caso, a su expresión más eficaz.

Como en el uso del lenguaje, en la elaboración y trayectoria de sus criaturas, Benet se permite una libertad totalmente lúdica. Tal derroche verbal y tales estallidos de la fantasía nos llevan casi a creer en lo que -contra lo que sostienen sus críticos- declara: "En definitiva, el último [problema] que me plantearía es el sociológico, la pregunta ¿para qué?, que no me preocupa nada. Escribo, en definitiva, porque me distrae, me entretiene..."12. Y esto nos lleva a pensar en los múltiples acertijos y rompecabezas que propone al lector cándido, en la sonrisa que se adivina a través de ellos, y en lo interesante que resultaría una indagación sobre el humor en Juan Benet.

Teresa Aveleyra A.

El Colegio de México.

11 Marisa M. Lázaro, "Juan Benet o la incertidumbre como fundamento", Uro., 1971, núms. 11 y 12; artículo cuyo título es definitorio del arte de Benet.

12 A. NúNEZ, op. cit. 